\title{
Modeling late Pliocene climate variability
}

\author{
Alan Haywood', H. Dowsett ${ }^{2}$, E. McClymont ${ }^{3}$ and U. Salzmann ${ }^{4}$ \\ Leeds, UK, 29 February - 1 March 2016
}

Thirty members of the PlioVAR working group met to discuss high-resolution proxy records and strategies for new experiments using climate models that will enable an enhanced appreciation and understanding of climate variability during the Late Pliocene.

The workshop began with a series of presentations reviewing high-resolution proxy records for the Late Pliocene. Presentations then focused on previous studies using climate models to predict climate variability during the Pliocene to provide the necessary scientific context for the workshop.

From the presentations and subsequent discussions, a number of key scientific questions and priorities emerged that will provide a focus for activities of the working group and wider scientific community. These include:

\section{Characterizing Pliocene "Warm" and "Cold" climate states at a gross level}

How does the environment change during warm and cold climate states of the Late
Pliocene? How do such variations between warm and cold compare to glacial/ interglacial climate variability of the Late Pleistocene? What is the relationship between climate and $\mathrm{CO}_{2}$ variability during the Late Pliocene and how does this compare to the Late Pleistocene? Going beyond basic reconstructions of temperature, what broader Earth system responses can be linked with climate variability in the Late Pliocene? This will include consideration of ice-sheet behavior, as well as other factors such as dust, which can be addressed using a combined geological data and Earth System Modeling approach.

\section{Understanding the M2 "glacial" event} Marine Isotope Stage (MIS) M2 is well represented as a positive isotope excursion in many benthic oxygen isotope records (Fig. 1). The event has been described as the failed onset of Northern Hemisphere Glaciation, but its character and significance remains highly uncertain. Targeted data acquisition will continue to improve our conceptual models of the climate transition

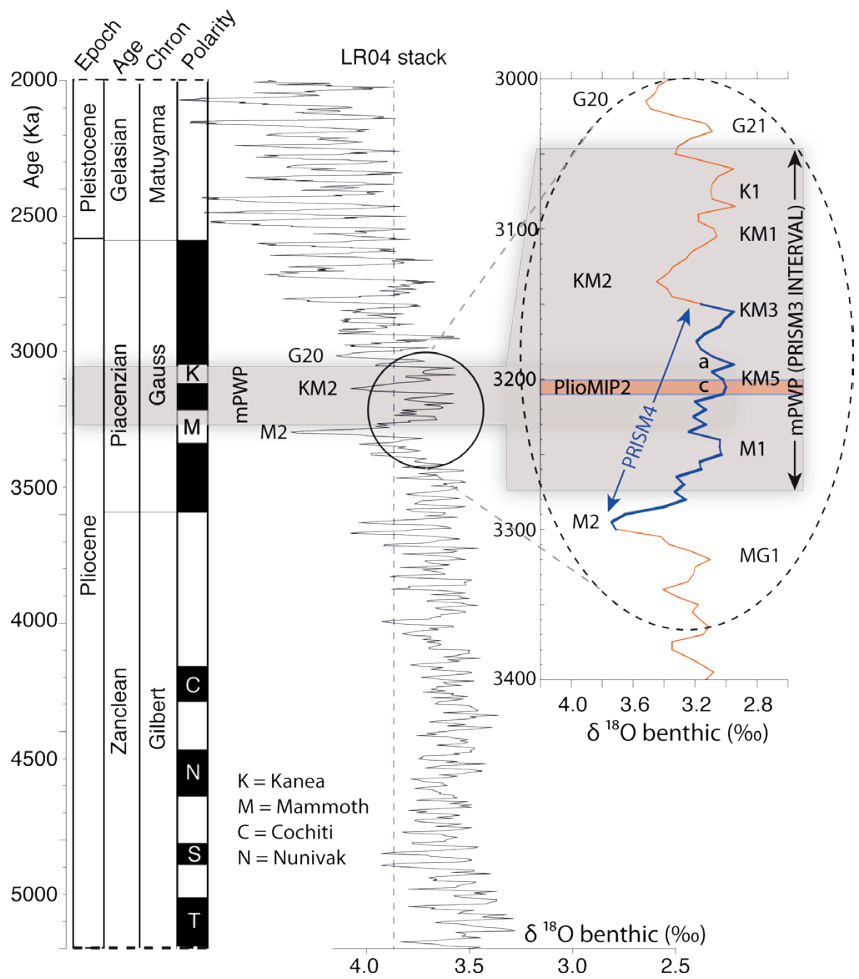

Figure 1: The PlioVAR interval of interest in relation to the long-term climate evolution of the late Pliocene. Shown is the global LR04 benthic oxygen isotope stack and timescale of Lisiecki and Raymo (2005). Vertical dashed line shows present day $\delta^{18} \mathrm{O}$ value. The mid-Pliocene warm period (mPWP) or PRISM3 warm interval (3.264-3.025 Ma) is shown by the horizontal shaded grey bar. The inset shows details for the MPWP and position of PlioVAR/PRISM4 and PlioMIP2 focus. Positions of Marine Isotope Stages MG1, M2, M1, KM5, KM3, KM2, KM1, K1, G21 and G20 are provided. into $\mathrm{M} 2$, including the difference between the response of the deep ocean and ocean surface. Climate modeling will be used to explore potential constraints on the M2 event using a well-known strategy of fingerprinting. Through a coordinated international effort, single forcing mechanisms of potential relevance to the $\mathrm{M} 2$ will be identified and incorporated into new experiments. These include orbital forcing, atmospheric trace gasses, plausible ice-sheet configurations, vegetation response and the importance of specific ocean gateways (e.g. Central American Seaway). The results of these simulations will be compared to available proxy data to determine what forcings, and forcing combinations, allow climate models to more reliably predict regional climate responses for the M2.

\section{Understanding the climate transition} from the M2 event to KM5

The transition out of the M2 event is just as enigmatic as the development of the event itself, but it heralded a period of relative climatic stability and equability until the end of MIS KM5 (Fig. 1). The period between M2 and KM5 intersects the warm interval selected for Phase 2 of the Pliocene Model Intercomparison Project (KM5c). Therefore, short high-resolution proxy time series from M2 to KM5 provide an opportunity to contribute towards data-model comparison and model evaluation exercises associated with PlioMIP, enhancing the capabilities of data-model synergy in the future.

PlioVAR is planning additional workshops during the next two years, as well as gathering at future EGU General Assemblies and AGU Fall meetings. Anyone interested in contributing to the project is encouraged to participate. The time, date and location of the meetings will be advertised through the PAGES website and e-news, and the PlioVAR mailing list.

\section{AFFILIATIONS}

'School of Earth \& Environment, University of Leeds, UK 2U.S. Geological Survey, Reston, USA ${ }^{3}$ School of Geography, Durham University, UK ${ }^{4}$ Department of Geography, Northumbria University, Newcastle, UK

\section{CONTACT}

Alan Haywood: earamh@leeds.ac.uk

\section{REFERENCE}

Lisiecki LE, Raymo ME (2005) Paleoceanography 20, doi: 10.1029/2004PA001071 